\title{
REFLEXÕES SOBRE A PRECARIZAÇÃO DO TRABALHO NA ASSISTÊNCIA SOCIAL DO MUNICÍPIO DE DUQUE DE CAXIAS/RJ.
}

\author{
Daniel Albuquerque Rocha - (PUCRJ) \\ Marcio Eduardo Brotto - (PUCRJ)
}

Reflexões sobre a Precarização do Trabalho na Assistência Social do município de Duque de Caxias/RJ., buscando dimensionar os processos de atenção à população residente neste município, levando em consideração as múltiplas expressões da Questão Social que a população é exposta.

O município de Duque de Caxias, localizado na baixada fluminense do Estado do Rio de Janeiro, tem a segunda maior arrecadação do Estado (IBGE 2013). Sendo rodeada pelo contraste social de um polo petroquímico que gera riquezas que não contribuem de forma efetiva na melhoria da qualidade pela redução dos processos de desigualdade social que atingem contingente significativo dos moradores dos diferentes territórios. Segundo Brotto:

\begin{abstract}
Assim, a contradição entre essas "duas Caxias", uma pobre, e outra rica, tem como síntese a compreensão de que o modelo de desenvolvimento do município está pautado na predominância do fiscal sobre o social, conforme demonstrado pelo fato de que, em 2011, os investimentos em assistência social representaram apenas $0,11 \%$ do PIB municipal. Isso explica porque, de um lado, Duque de Caxias ostenta a posição de segundo maior PIB estadual, e décimo quinto do país lado, apresenta um Índice de Desenvolvimento Humano (IDH) de 0,753, inferior à média de 0,764 obtida pelo Estado do Rio de Janeiro, ocupando a $52^{\mathrm{a}}$ posição entre os municípios fluminenses. Deste modo, Duque de Caxias, do passado ao presente: influências da história e cultura política na gestão democrática ...em que pese apresentar altos níveis de arrecadação fiscal, praticamente limita as suas ações - no campo da assistência social - àquelas organizadas, criadas e financiadas pela esfera federal e estadual. (Brotto, 2015, p. 200).
\end{abstract}

Exemplo expressivo para essa disparidade é o bairro de Jardim Gramacho onde durante anos esteve presente o aterro sanitário, local onde a questão social nas suas mais variadas contradições se expressa intensamente perversa e desumana, atingindo famílias que não se reconhecem como sujeitos de direitos.

Frente a tal quadro, devemos refletir como se encontra organizada e se articula a Rede Sócio Assistencial no município, buscando dimensionar em que medida as ações empreendidas estão contribuindo de forma concreta ao processo de enfrentamento das questões sociais e viabilizando alterações significativas na realidade dentro de uma perspectiva de acesso, garantia e efetivação de direitos, mas de ampliação dos processos de participação social e política, fortalecendo e potencializando a melhoria da qualidade dos serviços e da qualidade de vida.

Marx aponta para importância do estudo acerca da origem das expressões da questão social , o que permite afirmar que para além do lucro ela, a mais-valia, também gera a exploração da mão de obra do trabalho. Todo esse processo passa a se delinear a 


\section{SEMINÁRIO DE PESQUISA EM CIÊNCIAS HUMANAS - SEPECH \\ Humanidades, Estado e desafios didático-científicos \\ Londrina, 27 a 29 de julho de 2016}

partir da industrialização, quando se cria uma classe operária urbana fruto da expansão das cidades, cujas consequências se expressam, dentre outros aspectos: no excedente de mão de obra; no rebaixamento de salários; na ampliação da jornada de trabalho. Segundo Thompson (1989, p.10):

“a Classe Operária, esteve presente ao seu próprio fazer-se, colocando limites às condições de exploração do trabalho apresentadas pelo sistema capitalista, numa forma de resistência às novas ordens impostas pelas transformações sobre o processo de trabalho, buscando, com isso, seus interesses, seus direitos e formando-se assim enquanto classe. (...) a classe acontece quando alguns homens, como resultado de experiências comuns, sentem e articulam a identidade de interesses entre si”.

Podemos analisar assim que a classe trabalhadora vive uma alienação por não ter se organizado de forma adequada perante o capital, sendo assim uma classe que dentro do projeto capitalista, nunca deterá o capital sendo excluída e deslocada para as periferias sociais.

\section{HISTORICO E AS DIFICULDADES DA ASSISTENCIA EM DUQUE DE CAXIAS}

A problematização do objeto proposto nesse artigo requer de forma breve historicizar a história do município, haja vista que possibilita a compreensão de sua realidade atual. O Município de Duque de Caxias tem o inicio do seu povoamento datado do século XV quando Brás Cubas, provedor da Fazenda Real e das capitanias de São Vicente e Santo Amaro, recebeu, em doação de 3.000 braças de terras de testada para o mar e 9.000 braças de terras de fundo para o Rio Meriti. Outro dos agraciados foi Cristóvão Monteiro, que recebeu terras às margens do Rio Iguaçu. A principal atividade econômica era o cultivo da cana-de-açúcar.

Nos séculos XVII e XVIII, a divisão administrativa seguia critérios eclesiásticos, ou seja, a igreja assumia a responsabilidade jurídica e religiosa, administrando seu território. A região tornou-se nesse período importante ponto de passagem das riquezas vindas do interior do país como: o ouro das Minas Gerais e o café, que representaram cerca de setenta por cento de toda a economia brasileira desta época.

Apesar do declínio da mineração, a região conseguiu manter-se como importante ponto de abastecimento de tropeiros, de transbordo e de trânsito de mercadorias. No inicio do século XIX, o progresso da região foi bastante relevante tendo em vista as demais regiões. Porém devido à devastação desenfreada e a criação de mangues e pântanos, o que causou uma infestação de doenças infecto contagiosas que devastaram a região, a população que sobrou acabou migrando para outras áreas o que causou um abandono desta região e um esquecimento por parte dos governantes que, dada as características atuais se refletem até a atualidade.

Com a abolição da escravidão promulgada em 1888 trouxeram repercussões expressivas na vida econômica e social da Baixada Fluminense. Uma delas foi o esvaziamento e abandono de obras de saneamento básico o que levaram a agravos principalmente na saúde, acarretando epidemias de malária e a doença de Chagas. 


\section{SEMINÁRIO DE PESQUISA EM CIÊNCIAS HUMANAS - SEPECH \\ Humanidades, Estado e desafios didático-científicos \\ Londrina, 27 a 29 de julho de 2016}

Situação essa que só teve alterações no Governo de Getúlio Vargas cujas ações de limpeza de rios e lagos da região, diminuíram drasticamente a incidência de doenças.

Com a inauguração de novas estações da linha férrea, em 1911 pela Estrada de Ferro Leopoldina, multiplicaram-se as viagens, bem como o número de passageiros em Gramacho, São Bento, Actura (Campos Elísios), Primavera e Saracuruna, o que ligou definitivamente a região ao então Distrito Federal.

Somente no século $\mathrm{XX}$, se deu um crescimento demográfico acentuado na região, aprofundando as problemáticas existentes, principalmente de saneamento básico, tendo em vista que o território passou a servir de escoamento para a população excedente do Distrito Federal.

Com a abertura da Rodovia Rio-Petrópolis (hoje Rodovia Washington Luís) em 1928, a região voltou a prosperar com a instalação de inúmeras empresas que se instalaram na região devido à proximidade com o Rio de Janeiro.

O crescimento econômico gerado levou o deputado federal Manuel Reis a propor a criação do Distrito de Caxias, que ocorreu em 14 de março de 1931, através de ato do interventor Plínio de Castro e, em 31 de dezembro de 1943, através do decreto-lei 1.055, elevou-se à categoria de município, recebendo o nome de Duque de Caxias. Já a comarca de Duque de Caxias foi criada pelo decreto-lei ${ }^{\circ} 1.056$, no mesmo dia, mês e ano. O poder executivo foi instalado oficialmente em $1^{\circ}$ de janeiro de 1944 . O primeiro prefeito eleito foi Gastão Glicério de Gouveia Reis, que administrou a cidade de setembro de 1947 a dezembro de 1950.

Depois dele vieram, também eleitos pelo voto direto, respectivamente, Braulino de Matos Reis, Francisco Correa, Adolpho David, Joaquim Tenório Cavalcante e Moacir Rodrigues do Carmo. As eleições foram interrompidas com a decretação de Duque de Caxias como Área de Segurança Nacional pelo regime militar em 1971, tendo tomado posse o presidente da câmara, Francisco Estácio da Silva. A partir daí, por vezes contra a vontade das lideranças políticas e populares da região, foram eleitos prefeitos, pela ditadura militar, o general Carlos Marciano de Medeiros, os coronéis Renato Moreira da Fonseca, Américo Gomes de Barros Filho e o ex-deputado Hydekel de Freitas Lima.

O município conquistou, depois de muita movimentação de lideranças políticas, empresariais, sindicais e comunitárias, a sua autonomia em 1985, tendo sido eleitos, daquele ano em diante, Juberlan de Oliveira, Hydekel de Freitas Lima (em 1990, deixou o cargo para assumir uma cadeira no Senado Federal), José Carlos Lacerda (viceprefeito de Hydekel, tomou posse após sua renúncia), Moacyr Rodrigues do Carmo, José Camilo Zito dos Santos Filho e Washington Reis de Oliveira, sendo que o penúltimo retornou à prefeitura em 2009.

Nos dias atuais o Município de Duque de Caxias tem como seu gestor Alexandre Aguiar Cardoso e atualmente, como base nos dados produzidos pelo IBGE 2013 a população de Duque de Caxias é estimada em 873.921 mil pessoas distribuídas pelos $467,619 \mathrm{Km}^{2}$, sendo que $53,53 \%$ dessa população se encontram em estado de pobreza. Apesar de contar com empresas como a Petrobras e a Refinaria Duque de Caxias (REDUC) a riqueza produzida nesta região não é socializada pela geração de investimentos que atinjam as questões sociais de forma a gerar qualidade de vida à sua população, levando a abismos extremos, convivem lado a lado a REDUC e o Aterro Sanitário de Gramacho. 


\section{SEMINÁRIO DE PESQUISA EM CIÊNCIAS HUMANAS - SEPECH \\ Humanidades, Estado e desafios didático-científicos \\ Londrina, 27 a 29 de julho de 2016}

Nesse artigo observamos que no município de Duque de Caxias fica evidenciando não apenas por meio da apreensão teórica sobre a realidade como também pela atuação junto ás questões trazidas pelas famílias usuárias dos serviços ofertados pelo Lar Fabiano de Cristo em Campos Elíseos onde a se expressa de forma relevante esta realidade.

Pois apesar de ser um dos municípios mais ricos e prósperos do Brasil, o crescimento demográfico e o crescimento econômico advindo das empresas e indústrias que se implementaram em seu entorno não levaram à um desenvolvimento social compatível com reflexos objetivos e substantivos na realidade e condições de vida da população.

Assim como investimentos na mesma proporção de ações consonantes com as políticas públicas sociais na perspectiva de garantia de direitos.

Dentro deste cenário e partindo tanto da experiência profissional como da observação e reflexão, ainda que seja de forma empírica se encontra a rede sócio assistencial surgiu a inquietude e o interesse pela investigação de forma mais aprofundada e qualificada de sua organização, articulação e atuação junto à população.

Segundo Brotto:

ganha destaque o papel dos centros sociais em Duque de Caxias, sendo possível afirmar que eles ocuparam lacunas deixadas pela "inoperância do poder público". Nesse sentido, destacou-se que a insuficiência da rede socioassistencial pública manifesta-se de variadas formas, desde a ausência de equipamentos socioassistenciais até a má distribuição no território municipal. (Brotto, 2015, p. 209).

As impressões observadas da rede sócio assistencial no município de Duque de Caxias suscitam indagações e reflexões acerca de processos de fragmentação, desarticulação e paralelismos que fragilizam e criam entraves e/ou obstaculizam a construção de vínculos no atendimento à população e uma maior e qualificada participação desta nas ações propostas e implementadas.

Essa relação foi percebida tanto no âmbito do atendimento de instituições privadas, como nos mecanismos públicos, dentre eles o CRAS enquanto responsável por empreender ações de Proteção Básica e o CREAS de média e alta complexidade.

A partir dos atendimentos sociais junto às famílias de Campos Elísios, bairro localizado na periferia do Município de Duque de Caxias, e que tem como fator determinante para essa observação o fato de sua população viver expostas às múltiplas expressões da Questão Social, na qual destacamos a pobreza. Segundo Montaño:

a pobreza nasce deficitária. É visto como um problema de planejamento das famílias e como problemas de ordem moral-comportamental. A pobreza passa a ser reprimida e castigada, como sendo uma questão criminal dos pobres. Os abrigos passam a ser substituídos pela reclusão dos pobres. A expressão "marginal" começa a adquirir uma conotação de "criminalidade".( Montaño 2012)

Dentro dessa realidade as famílias são penalizadas e seus direitos sociais não são reconhecidos e efetivados de forma plena conforme os marcos jurídicos presentes em nossa sociedade como a Constituição Federal de 1988, Política Nacional de Assistência 


\section{SEMINÁRIO DE PESQUISA EM CIÊNCIAS HUMANAS - SEPECH \\ Humanidades, Estado e desafios didático-científicos \\ Londrina, 27 a 29 de julho de 2016}

Social (PNAS), Sistema Único de Assistência Social (SUAS) e os Estatutos do Idoso, da Criança e do Adolescente e da Juventude.

A Constituição Federal de 1988 em seu artigo terceiro nos diz que:

Art. $3^{\circ}$ Constituem objetivos fundamentais da República Federativa do Brasil:

I - construir uma sociedade livre, justa e solidária;

II - garantir o desenvolvimento nacional;

III - erradicar a pobreza e a marginalização e reduzir as desigualdades sociais e regionais;

IV - promover o bem de todos, sem preconceitos de origem, raça, sexo, cor, idade e quaisquer outras formas de discriminação.

O artigo citado explicita de forma clara que é dever do Estado garantir que a população tenha acesso aos seus diretos sociais de forma plena e absoluta, fato este que diverge da realidade observada e apresentada no Município de Duque de Caxias.

Estes direitos sociais também estão explicitados na Constituição de 1988 como podemos observar no artigo sexto:

Art. $6^{\circ}$ São direitos sociais a educação, a saúde, a alimentação, o trabalho, a moradia, o lazer, a segurança, a previdência social, a proteção à maternidade e à infância, a assistência aos desamparados, na forma desta Constituição.

Esse é um ponto central deste artigo, pois o Estado ao não garantir os direitos sociais previstos na Constituição acaba por promover muito mais uma desconcentração sem uma real descentralização que possibilite autonomia nos níveis de gestão e reduz investimentos e precariza ações que fortalecem uma perspectiva de Estado mínimo, enfraquecendo as instituições públicas como escolas, postos de saúde, hospitais, entre outros e financia a sociedade civil a prover mecanismos de apoio a essa população através de Organizações Não Governamentais e Instituições Filantrópicas e Empresariais. Com isso, fortalece uma "Sociedade de Bem-Estar" em detrimento de um real Estado Democrático de Direitos. Estas instituições de atendimento, sejam elas públicas ou privadas, possuem dificuldades de dialogar de maneira eficaz entre si, causando uma exposição da população de "desatenção". Como exemplo, podemos citar as escolas da região que funcionam em cinco turnos, com horários completamente diferentes, o que dificulta a inserção das crianças em projetos sociais, e enfraquecem a atuação de rede, pois as instituições, por sua vez, não interagem e buscam se fortalecer para criar canais de discussão e ações coletivas, se adaptando à realidade apresentada no Município.

Segundo a Constituição de 1988 cabe aos Munícipios:

Art. 30. Compete aos Municípios:

I - legislar sobre assuntos de interesse local;

II - suplementar a legislação federal e a estadual no que couber;

III - instituir e arrecadar os tributos de sua competência, bem como aplicar suas rendas, sem prejuízo da obrigatoriedade de prestar contas e publicar balancetes nos prazos fixados em lei; 


\section{SEMINÁRIO DE PESQUISA EM CIÊNCIAS HUMANAS - SEPECH \\ Humanidades, Estado e desafios didático-científicos \\ Londrina, 27 a 29 de julho de 2016}

IV - criar, organizar e suprimir distritos, observada a legislação estadual;

V - organizar e prestar, diretamente ou sob regime de concessão ou permissão, os serviços públicos de interesse local, incluído o de transporte coletivo, que tem caráter essencial;

VI - manter, com a cooperação técnica e financeira da União e do Estado, programas de educação infantil e de ensino fundamental;

VII - prestar, com a cooperação técnica e financeira da União e do Estado, serviços de atendimento à saúde da população;

VIII - promover, no que couber, adequado ordenamento territorial, mediante planejamento e controle do uso, do parcelamento e da ocupação do solo urbano;

IX - promover a proteção do patrimônio histórico-cultural local, observada a legislação e a ação fiscalizadora federal e estadual.

Com base no acima disposto, caberia ao Município em ser de primeira instancia a promoção do bem estar de sua população, com prática qualiquantitativas que possam atingir a seus cidadãos.

Outro marco jurídico-legal importante se vincula à análise vinculada ao Sistema Único de Assistência Social (Suas), que segundo o Ministério do Desenvolvimento Social e Combate à Fome (MDS) é:

Um sistema público que organiza, de forma descentralizada, os serviços socioassistenciais no Brasil. Com um modelo de gestão participativa, ele articula os esforços e recursos dos três níveis de governo para a execução e o financiamento da Política Nacional de Assistência Social (PNAS), envolvendo diretamente as estruturas e marcos regulatórios nacionais, estaduais, municipais e do Distrito Federal.Coordenado pelo Ministério do Desenvolvimento Social e Combate à Fome (MDS), o Sistema é composto pelo poder público e sociedade civil, que participam diretamente do processo de gestão compartilhada. (Site do Ministério do Desenvolvimento Social e Combate a Fome - Acesso 23/04/2016)

Sendo assim, o SUAS é uma ferramenta de gestão importantíssima para direcionar as ações na garantia dos direitos sociais da população.

O SUAS é dividido em duas ações de proteção social, conforme nos mostra o Ministério do Desenvolvimento Social e Combate à Fome (MDS). Sendo o SUAS o organizador das ações da Assistência Social, ele é o responsável por garantir os direitos sociais da população de forma global no embate as múltiplas expressões da Questão Social, tanto na prevenção quanto no enfrentamento das mazelas sociais.

O Suas organiza as ações da assistência social em dois tipos de proteção social. A primeira é a Proteção Social Básica, destinada à prevenção de riscos sociais e pessoais, por meio da oferta de programas, projetos, serviços e benefícios a indivíduos e famílias em situação de vulnerabilidade social. A segunda é a Proteção Social Especial, destinada a famílias e indivíduos que já se encontram em situação de risco e que tiveram seus direitos violados por ocorrência de abandono, maus-tratos, abuso sexual, uso de drogas, entre outros aspectos. (Site do 


\section{SEMINÁRIO DE PESQUISA EM CIÊNCIAS HUMANAS - SEPECH \\ Humanidades, Estado e desafios didático-científicos \\ Londrina, 27 a 29 de julho de 2016}

Ministério do Desenvolvimento Social e Combate a Fome - Acesso

23/04/2016)

Essa realidade encontrada no município de Duque de Caxias, me fez postular o aprofundamento de estudos sobre a rede sócio assistencial do município. Para tentar responder a estes questionamentos, apresenta-se como propostas de trabalho:

- $\quad$ Analisar a organização e articulação da rede socioassistencial do município de Duque de Caxias tanto no âmbito privado e público junto à população.

- $\quad$ Evidenciar as formas de articulação da rede socioassistencial do Município de Duque de Caxias;

- Identificar os principais fatores que levam a falta de articulação entre o âmbito privado e o âmbito público;

- Verificar a existência e formas de articulação junto à população no fortalecimento da Participação e Controle Social

A Assistência Social no Brasil organizou-se a partir do binômio entre, a atividade assistencial privada, de cunho filantrópico, que marca a ação das diferentes organizações comunitárias e sociais e a introdução das primeiras políticas públicas.

Com a promulgação da Constituição Federal de 1988, determinou-se que a assistência social passa a ser efetuada juntamente com o sistema de seguridade social brasileiro, junto também com a saúde e a previdência. Passando assim a ser direito do cidadão e dever do Estado.

Já a Política Nacional de Assistência Social - PNAS/2004 foi elaborada através de um longo processo de embates liderados pelo Ministério de Desenvolvimento Social MDS, ela é uma política que tem por objetivo a aplicação das políticas setoriais, garantindo os mínimos sociais e à universalização dos direitos sociais.

Essas políticas implementadas tem por objetivo enfrentar a exclusão social que esta população é exposta pela falta de serviços essenciais para seu desenvolvimento e sobrevivência. Segundo Castel:

a exclusão social se dá efetivamente pelo estado de todos os que se encontram fora dos circuitos vivos das trocas sociais. A exclusão social nomeia situações que traduzem uma degradação relacionada a um posicionamento anterior. O excluído é de fato um desfiliado cuja trajetória é feita de uma série de rupturas.

Essa camada da população expostas às múltiplas expressões da Questão Social está cada vez mais oprimida pelo modo de produção capitalista. Essa camada da sociedade não está inserida como consumidora dos direitos e do serviços impostos pelo capital. Santos afirma que:

"É importante destacar aqui duas questões. A primeira delas é que não se está designando como "questão social" a desigualdade e a pobreza indistintamente e sim aquelas que têm sua existência fundada pelo modo de produção capitalista. Isso tem por suposto o reconhecimento de outras "formas de ser" (Marx) desses fenômenos que antecedem o capitalismo. No escravismo e no sistema feudal, existiam diferenciações 


\section{SEMINÁRIO DE PESQUISA EM CIÊNCIAS HUMANAS - SEPECH \\ Humanidades, Estado e desafios didático-científicos \\ Londrina, 27 a 29 de julho de 2016}

entre classes, propriedade privada e exploração do trabalho e, portanto, reproduzia-se a desigualdade. (2012, p.28 e 29)".

Para entendermos a rede sócioassistencial do Município de Duque de Caxias deve se observar a sua construção política social, sua forma de articulação e de desenvolvimento que o modo de produção capitalista é imposta a essa população.

Analisamos a expressão da Questão Social, Pobreza se expressando na deterioração da comunidade que compõe o referido município sua classe operária. Bresciane (1985, p.25), ao se referir às descrições de Engels acerca dos bairros onde se concentram a classe operária, destaca que:

no interior das moradias, nos pátios e nas ruelas transversais: não há um único vidro de janela intacto, os muros são leprosos, os batentes das portas e janelas estão quebrados, e as portas, quando existem, são feitas de pranchas pregadas. Nas casas até os porões são usados como lugar de morar e em toda parte acumulam-se detritos e água suja. Aí moram os mais pobres dentre os pobres, os trabalhadores mal pagos misturados aos ladrões, aos escroques e às vítimas da prostituição.

Ao analisarmos a Exclusão Social, nos propiciará e determinará uma reconfiguração no debate teórico e metodológico sobre a pobreza. Neste sentido:

a exclusão, tal como a pobreza, nasce como uma categoria do campo da ação, da intervenção, pois, sendo uma categoria identitária, visa designar e caracterizar o status social dos indivíduos que se situam na parte inferior da hierarquia social (...). Substituir o enfoque da pobreza pelo da exclusão social significa passar de uma ótica de patamares de carência para um enfoque dinâmico, cumulativo (...) onde o que se pretende é apreender o que transforma o risco decorrente da vivência da insegurança, instabilidade e precariedade, num estado fatal, levando a perda de visibilidade (LAVINAS, 2002, p. 38).

A exclusão social infere as estruturas da sociedade e seus componentes; configurando processos de reprodução das múltiplas expressões da Questão Social.

Não devendo de forma alguma realizar uma de forma fragmentada e sim analisando todos os fatores que levaram a grande parte da população do Município de Duque de Caxias a ser dependente das redes socioassistenciais sejam elas privadas e/ou públicas.

\section{REFERÊNCIAS BIBLIOGRÁFICAS}

BRASIL. Constituição (1988). Constituição da República Federativa do Brasil, Brasília, DF, Senado, 1988.

BRASIL. Política Nacional de Assistência Social - PNAS. Brasília, 2004. 


\section{SEMINÁRIO DE PESQUISA EM CIÊNCIAS HUMANAS - SEPECH \\ Humanidades, Estado e desafios didático-científicos \\ Londrina, 27 a 29 de julho de 2016}

BRESCIANI, Maria Stella M. Londres e Paris no século XIX: o espetáculo da pobreza. São Paulo: Brasiliense, 2004.

BROTTO. Marcio Eduardo. Assistência Social - História e Cultura Política. Rio de Janeiro; Editoras PUCRJ e Reflexão, 2015.

CASTEL, R. As armadilhas da exclusão social. In: CASTEL, R; WANDERLEY, L.E; BELFIORE-WANDERLEY, M. Desigualdade e a Questão Social. São Paulo: Educ, 2008.

COUTO, Berenice Rojas; YASBEK, Carmelita; SILVA E SILVA, Maria Ozanira da; RAICHELIS, Raquel. O Sistema Único de Assistência Social no Brasil: uma reali dade em movimento. São Paulo: Cortez, 2010.301p.

GRAMSCI, Antonio. Obras escolhidas. Tradução Manuel Cruz; revisão Nei da Rocha Cunha. São Paulo: Martins Fontes, 1978.

LAVINAS, Lena. Pobreza e exclusão: traduções regionais de duas categorias da prática. In: Econômica, Vol. 4, N 1, 2002, p. 25-59.

MONTAÑO, Carlos. Pobreza, "Questão Social" e seu enfrentamento. São Paulo, Serviço Social e Sociedade, n. 110, 2012.

NETTO, Jose Paulo. Desigualdade, pobreza e Serviço Social. Revista Em Pauta (Revista da faculdade de Serviço Social da UERJ), n.- 19, 2007.

. A construção ético-político do Serviço Social frete à crise contemporânea. In: Capacitação em Serviço Social e Política Social. Brasília: CEAD, Módulo I, 1999. . Transformações Societárias e Serviço Social. Notas para uma análise da profissão no Brasil In: Serviço Social e Sociedade, no . 50. São Paulo: Cortez, 1996. Ditadura e Serviço Social. São Paulo, Cortez, 1991.

SANTOS, Josiane Soares. "Questão Social”: particularidades no Brasil. São Paulo, Cortez Editora, 2012.

THOMPSON, Edward.Palmer. A Formação da Classe Operária Inglesa. Rio de Janeiro: Paz e Terra. 1989. V. 1.

WÜNSCH, Dolores Sanches e MENDES, Jussara Maria Rosa. A Classe Operária frente às transformações do trabalho: atualizando o debate. In: Revista virtual Textos \& Contextos, $\mathrm{n}^{\mathrm{o}}$ 2, Rio de Janeiro, 2003. Disponível em http://www.assistentesocial.com.br, acessado em agosto de 2012.

YAZBEK, Maria Carmelita. O Serviço Social na área de Assistência Social. São Paulo, 2004.

Sites visitados: 


\section{SEMINÁRIO DE PESQUISA EM CIÊNCIAS HUMANAS - SEPECH \\ Humanidades, Estado e desafios didático-científicos}

Londrina, 27 a 29 de julho de 2016

Ministério do Desenvolvimento Social e Combate a Fome - Disponível em: <>. http://www.mds.gov.br/assistenciasocial/suas - Acesso em 26.04.2016. 